UDC 316.334.22

LBC 60.59

\title{
ECONOMIC PRACTICES OF ARURAL LIFESTYLE IN RUSSIA AND COLOMBIA: A SOCIOLOGICAL ANALYSIS
}

\author{
Mikhail M. Krasnov \\ Pedagogical and Technological University of Colombia, Tunja, Colombia \\ Natalia A. Skobelina \\ Volgograd State University, Volgograd, Russian Federation
}

\begin{abstract}
The article analyzes the lifestyle activities of the rural population of Russia and Colombia in the economic sphere. The possibility of comparing data for both countries, provided by similar methods of statistical observations adopted by the statistical agencies of both countries, and the unified principles of organizing a sociological study conducted by the authors, is shown. The features of rural economic and economic practices identified through indicators of the labor market and employment are revealed. In Russia, these are the dominance of wage employment to the detriment of entrepreneurship, the high proportion of informal self-employment, in which agricultural activity predominates (with its systemic reduction in the official labor market), the growth of pendulum labor migration to cities. In Colombia, there are a steady dominance of agricultural activity in the field of rural employment, a high proportion of laborers and small non-agricultural businesses, usually informal, high employment of women in the household, and an increase in permanent labor migration to cities. It has been established that the main motivational factors of rural lifestyle practices are determined by living conditions and are the same in Russia and Colombia; are objective and rational. These include, first of all, the location of the village: proximity to the city everywhere promotes a plurality of labor strategies; changes in welfare and employment structure: abandonment of agricultural activities, job loss, low incomes stimulate self-employment, entrepreneurial activity and labor migration (pendulum and permanent) to cities. Rational, objectively conditioned motives lead to the emergence of essentially identical lifestyle practices, which may differ in forms and frequency of manifestation, reflecting national specificity. It is shown that a change in the external socio-economic environment causes a similar rational socio-behavioral reaction in rural society, regardless of national characteristics.
\end{abstract}

Key words: rural lifestyle, social practices, economic activity, employment, cross-country comparisons.

УДК 316.334 .22

ББК 60.59

\section{ХОЗЯЙСТВЕННО-ЭКОНОМИЧЕСКИЕ ПРАКТИКИ СЕЛЬСКОГО СТИЛЯ ЖИЗНИ В КОЛУМБИИ И РОССИИ: СОЦИОЛОГИЧЕСКИЙ АНАЛИЗ}

\author{
Михаил Михайлович Краснов \\ Университет педагогики и технологий Колумбии, г. Тунха, Колумбия \\ Наталья Анатольевна Скобелина \\ Волгоградский государственный университет, г. Волгоград, Российская Федерация
}

Аннотация. В статье анализируются стилежизненные деятельностные практики сельского населения России и Колумбии в хозяйственно-экономической сфере. Авторами показана возможность сопоставления 
данных по обеим странам, обеспечиваемая похожими методами статистических наблюдений, принятыми статистическими ведомствами обеих стран, и едиными принципами организации социологического исследования, проведенного авторами. Выявлены особенности сельских хозяйственно-экономических практик, определяемые через показатели рынка труда и занятости. В России это - доминирование занятости по найму в ущерб предпринимательству, высокий удельный вес неформальной самозанятости, в составе которой преобладает сельскохозяйственная деятельность - при ее системном сокращении на официальном рынке труда, росте маятниковой трудовой миграции в города. В Колумбии - устойчивое доминирование сельскохозяйственной деятельности в сфере сельской занятости, высокий удельный вес батрачества и мелкого несельскохозяйственного бизнеса, обычно неформального, высокий уровень занятости женщин, рост постоянной трудовой миграции в города. Установлено, что основные мотивационные факторы сельских стилежизненных практик являются объективными и рациональными и определяются условиями проживания в России и Колумбии. К их числу относятся, прежде всего, местоположение села: близость к городу всюду способствует множественности трудовых стратегий; изменение благосостояния и структуры занятости: отход от сельскохозяйственной деятельности, потеря работы, низкие доходы стимулируют самозанятость, предпринимательскую активность и трудовую миграцию (маятниковую и постоянную) в города. Рациональные, объективно обусловленные мотивы ведут к появлению одинаковых по сути стилежизненных практик, которые могут различаться по формам и частоте проявления, отражая национальную специфику. Показано, что изменение внешней социально-экономической среды вызывает у сельского социума, независимо от национальных особенностей, похожую рациональную социально-поведенческую реакцию.

Ключевые слова: сельский стиль жизни, социальные практики, хозяйственно-экономическая деятельность, занятость, межстрановые сопоставления.

\section{Введение}

Стиль жизни - сложная синтетическая категория, рассматриваемая в теории стратификации как основание дифференциации социальных групп, страт, слоев. Согласно М. Веберу, стиль жизни - это ежедневная деятельность и практика индивидов, различающаяся в зависимости от их принадлежности к определенной статусной группе и определяемая как его собственными представлениями и устремлениями, так и ожиданиями окружающих [Вебер 1990, 28; Вебер 1994]. Согласно концепции П. Бурдье, стили жизни структурируют социальное пространство: индивид стремится занять в нем определенную позицию, формируя соответствующим образом свой стиль жизни [Бурдье web].

Современные российские исследователи при анализе социального пространства в качестве основных его структурообразующих признаков выделяют виды деятельности, образующие стиль жизни [Парамонова, Дулина 2015, 31; Дулина 2017]; воспроизводящиеся социальные практики [Пасовец 2017, 91; Рощина web; Горбань web], экономические условия повседневности [Горшков, Крумм, Тихонова (ред.) 2009, 7-21].

В рамках классического подхода стиль жизни жестко идентифицируется с социальной группой. Современный подход оставляет за индивидом более широкие возможности для самореализации, учитывающие его собственные ценности и потребности. Акцент смещается к пониманию стиля жизни как личного выбора индивида, как способа его самоидентификации, определяемого не только «демонстративным потреблением» [Веблен 1984] большее внимание уделяется повседневным практикам в хозяйственно-экономической, бытовой, досуговой и прочих сферах.

«Размывание» стилей жизни в современную эпоху, их множественность, ведет к трудностям или невозможности отождествления конкретного стиля жизни с определенной социальной группой. Современный индивид меньше зависит от своего социального статуса в плане свободы выбора определенного стиля жизни, чем раньше. Иными словами, многие стилежизненные практики в различных сферах, прежде характерные для определенной социальной группы, в настоящее время в большей степени являются выбором самого индивида. Это меняет подход к пониманию стиля жизни: он часто рассматривается, как набор социальных практик, которые не связаны жестко с определенной социальной группой, а вся совокупность социальных практик образует социальное пространство в целом. Актуализируется идея П. Бурдье о том, что 
социальное пространство представляет собой структуру позиций индивидов, формирующуюся в зависимости от реализуемых практик.

Итак, стиль жизни определяется не только стремлением индивида идентифицировать себя с желаемой социальной группой: индивид учитывает также и те аспекты, которые важны лично для него, отражают его частные желания и потребности. Очевидно, одно не исключает другое, и между двумя современными подходами нет противоречия.

Стиль жизни определяется также возможностями индивида, поэтому важно рассматривать не только потребительские и досуговые стилежизненные практики, но и деятельностные практики, приносящую доход экономическую деятельность, которая мотивирована как экономическими причинами (необходимостью получения дохода), так и социальными (потребностью в профессиональной и статусной самореализации).

В настоящей статье мы рассматриваем стиль жизни в более широком аспекте - как следование системе норм в различных сфеpax, считающихся общепринятыми в данном социально-территориальном сообществе - в различных слоях сельского населения, - а не в конкретной социальной группе. Индивид стремится сочетать различные деятельностные практики - прежде всего в трудовой, хозяйственно-экономической сфере - как инструмент адаптации к внешним социально-экономическим условиям.

Итак, будем интерпретировать стиль жизни через систему социальных практик индивида, обусловленных его стремлением к успешной социально-экономической адаптации к нормам и требованиям «своего» социальнотерриториального сообщества с учетом собственных потребностей и возможностей. Одни из наиболее значимых социальных практик относятся к хозяйственно-экономической сфеpe: их сочетанием индивид обеспечивает свои практические возможности вести желаемый стиль жизни.

Цель статьи: в ходе социологического анализа выявить общие и специфические черты в хозяйственно-экономических практиках сельского населения России и Колумбии.

Эмпирическая база исследования: методические разработки и статистические материалы Федеральной службы государственной статистики России (Росстата) и департамента статистики Колумбии [Федеральная... web; Departamento... web]; материалы авторского социологического исследования, включающего серию интервью (2020 г.) и анкетный опрос (2017-2018 гг.), проведенный на базе вероятностных стратифицированных выборок объемом $\mathrm{N}=426$ (Россия, Саратовская область) и $\mathrm{N}=414$ (Колумбия, Центральная провинция), сформированных с учетом половозрастных структур сельского населения 20 лет и старше соответствующих регионов.

\section{Результаты}

В последние годы растет актуальность межстрановых социальных исследований, что определяется, в частности, противоречивостью процессов глобализации и регионализации, усиливающих социальное многообразие современного мира. Подобные исследования позволяют обществу увидеть себя «со стороны», более четко осознать параметры сходства и различия с другими странами.

По мнению А.В. Андреенковой, «сравнительные межстрановые социологические исследования, основанные на опросных методах, - одни из наиболее сложных в методологическом, теоретическом и техническом планах» [Андреенкова 2011]. Их основная сложность - необходимость достижения сопоставимости опросного листа, выборок в странах проведения исследования, итоговых группировок. Для этого нами был разработан инструментарий, предусматривающий эквивалентность базовых понятий и их операционализацию в виде вопросов анкеты; были учтены возможные различия в стиле коммуникации респондентов в разных странах.

Возможность межстранового анализа социально-экономических показателей, связанных со стилем жизни, достигается тем, что в статистических ведомствах России и Колумбии используются одинаковые или похожие концепции статистических наблюдений. В частности, в целом совпадают методики проведения бюджетных обследований домашних хозяйств и обследований занятости, что делает сопоставимым результаты анализа по обеим странам [Российский... web, 183; Encuesta... web]. 
Выбор Колумбии в качестве страны для сравнения с Россией характеристик сельских стилей жизни определяется:

- социально-экономической, демографической, культурной непохожестью обеих стран и, одновременно с этим, их сопоставимостью по этнокультурному и природно-ландшафтному многообразию. Данные факторы (непохожести и сопоставимости) детерминируют разнообразие сельских стилежизненных практик, тем самым повышая возможности выявления как специфических среди них, связанных с конкретной страной, так и общих;

- сходством хозяйственно-экономической деятельности сельского населения в обеих странах, отражающей существенные проблемы узости сельского рынка труда и социальной неоднородности.

Хозяйственно-экономическая деятельность сельского населения в России имеет своей особенностью активное сочетание основной официальной работы, чаще всего не связанной с сельским хозяйством, и неформальной, как правило, сельскохозяйственной. В 2019 г. неформальная занятость охватывала $30,3 \%$ общего числа работающих сельских жителей старше 14 лет (против 17,8 \% горожан того же возраста). В основном неформальная занятость сельского населения в России - это хозяйственно-экономические практики в сельском хозяйстве (37,8 \%), торговле, ремонте, гостиничном бизнесе (около $26 \%)$, строительстве $(9,8 \%)$. Видовая структура деятельностных практик сельского населения на основной работе заметно отличается: в сельском хозяйстве работают только 19,2 \% занятых, в торговле, ремонте, гостиничном бизнесе $14,7 \%$, в строительстве $6,9 \%$; более $20 \%$ заняты в бюджетной сфере - в образовании, здравоохранении, предоставлении социальных услуг. Сельскохозяйственные практики сельского населения России, которые до реформ доминировали в структуре сельской занятости, в настоящее время в значительной мере перешли в неформальную сферу, по большей части в личные подсобные хозяйства (ЛПХ).

Важно отметить, что деятельностные практики в неформальном секторе рынка труда России гораздо чаще, чем в официальном секторе, носят предпринимательский харак- тер или относятся к самозанятости - 36,5 \% против $7 \%$ [Обследование... web]. То есть деятельностные практики, основанные на предпринимательстве и самозанятости, в России часто остаются «в тени», носят вторичный и неформальный характер [Барсукова, Радаев wеb].

Приведенные данные свидетельствует о существовании значительного перекоса в направлении занятости по найму сельского населения России в ущерб самостоятельной и предпринимательской занятости. Это обусловлено сложностями организации и ведения малого бизнеса в стране. В то же время предпринимательские практики получили широкое распространение в сфере вторичной и неформальной занятости.

В трудовой занятости сельского населения Колумбии доминируют сельскохозяйственные практики, причем, с течением времени их удельный вес в видовой структуре занятых практически не меняется. И в 2002 г., и в 2019 г. он составил 60-61\% от общего числа сельских занятых. Сельское хозяйство оттягивает на себя большинство сельских занятых, и на остальные виды деятельности приходятся гораздо меньшие доли: на торговлю, ремонт, гостиницы - 13,4 \% в 2019 г., на образование, здравоохранение, социальные услуги - 5,2 \%. Можно говорить о медленной диверсификации сельской экономики в Колумбии и об общем отставании сельского развития. Однако, одновременно с этим отметим, что при трехкратной разнице удельного веса сельскохозяйственной занятости сельского населения в Колумбии и России ( $60 \%$ против $19 \%$ ) доля занятых в сфере услуг - торговли, ремонта и т. п. - очевидно, относящихся к частному сектору экономики, практически совпадает. Это свидетельствует о большей по сравнению с Россией ориентированности сельского населения Колумбии на предпринимательские практики в хозяйственно-экономической сфере.

Анализ профессионально-статусной структуры занятого сельского населения Колумбии подтверждает слабое вмешательство государства в экономическую деятельность. Это выражается в низком уровне занятости в государственных компаниях и в бюджетной сфере $-4,7 \%$ в 2019 г. Занятость по найму в частном секторе довольно высокая - 20,4 \% 
от общего числа сельских занятых. При этом, как и в России, значительна неформальная самозанятость: хозяйственно-экономические практики в этой сфере в 2019 г. охватывали половину всех сельских занятых, причем, с течением времени этот охват расширяется (с $43 \%$ в 2002 г.). В то же время самозанятость в Колумбии - это в основном мелкий бизнес, чаще всего несельскохозяйственный и не вторичный, как в России, а основной, едва позволяющий сводить концы с концами.

Отметим еще одно характерное направление в профессионально-статусной структуре сельского населения Колумбии - батрачество. Оно связано с бедностью и отражает архаичные, отсталые социальные практики. Его удельный вес остается довольно высоким - $14 \%$ в 2019 г., хотя и имеет выраженную тенденцию к снижению (с 18 \% в 2002 г.). В России к батрачеству можно с некоторой натяжкой отнести сезонный неквалифицированный сельскохозяйственный труд, сопоставимые данные по которому официальная российская статистика не содержит.

Еще один показатель, отражающий архаичные, отсталые социальные практики, связан с занятостью сельского населения в домашнем хозяйстве без оплаты труда, представленной в основном женщинами-домохозяйками. Рассмотрим отдельно показатель занятости сельских женщин. Высокая социальная значимость этого показателя состоит в том, что он характеризует степень эмансипации сельских женщин и, в конечном счете, показывает, насколько общество модернизировано в социально-гендерном отношении. В принципе, уровень занятости женщин во всех странах ниже, чем у мужчин, причем, в сельской местности разница более значительная, чем в городах. Эта разница в России и в развитых странах в большей степени связана с биолого-социальными особенностями полов (отпуск по уходу за детьми гораздо чаще берут женщины, а не мужчины) и более низким у женщин по сравнению с мужчинами возрастом выхода на пенсию. Поэтому «полное равенство» полов в сфере труда и занятости в принципе не достижимо ни в одной стране мира, сколь бы развитой она ни была.

Тем не менее, «избыточно низкая» занятость женщин в экономике и, одновременно с этим, «избыточно высокая» их занятость в домашнем хозяйстве является отражением социального статуса женщины, характерного для патриархального стиля жизни. В Колумбии в домашнем хозяйстве в 2019 г. было занято 63,3 \% сельских женщин старше 12 лет, в России $-28,4 \%$ сельских женщин старше 14 лет. Более высокий пороговый возраст экономической активности в России может не существенно повлиять на уровень занятости в сторону еще большего его снижения. При этом уровень занятости колумбийских городских женщин в домашнем хозяйстве заметно ниже - 39,3 \% (в России - 11,0 \% [Обследование... web; Encuesta... web]), что только подчеркивает «избыточно высокий» уровень занятости в домашнем хозяйстве сельских женщин в Колумбии.

Дальнейший анализ хозяйственно-экономических практик сельского населения был проведен на материалах анкетного опроса сельских респондентов в России и Колумбии.

Посредством анкетных вопросов об источниках доходов были выявлены факторы, способствующие повышению благосостояния и стабильному социально-экономическому положению сельского населения в Колумбии и России (см. табл. 1,2$)$. Это увеличение семейных доходов сельского населения России по сравнению с Колумбией, что проистекает из более высокой активности российских респондентов в выборе ответов. Кроме того, в российском селе более развита маятниковая трудовая миграция. Ее значительный масштаб означает, что экономически активное население российского села таким образом самостоятельно расширяет рамки узкого сельского рынка труда, меньше зависит от сельского работодателя и имеет высокие доходы, которые обеспечиваются занятостью в городской среде. Положительным фактором для колумбийского населения следует считать высокую активность в коммерческой сфере, например, в сфере малого бизнеса. Также позитивным является высокая доля частного сельскохозяйственного производства.

Приведенные в таблицах 1 и 2 данные позволяют также выявить факторы, которые затруднительно охарактеризовать однозначно в качестве позитивных или негативных. Так, 
в сельской России малый бизнес развивается медленно - его замещает предпринимательская деятельность в ЛПХ и дополнительные приработки, часто неофициальные, которые определяют нестабильный, небольшой заработок. Хозяйственная деятельность в личном хозяйстве (причем, часто мотивируемая не товарными, а потребительскими, реципрокными целями) и дополнительные приработки являются отражением архаичных черт сельского стиля жизни. Однако, в то же время, эти виды деятельности повышают социально-экономическую адаптивность и способствуют преодолению бедности сельского населения в России, а при проявлении им предпринимательской активности (например, увеличении продаж продукции ЛПХ) способствуют реальному повышению благосостояния и модернизации сельского стиля жизни.

По нашему мнению, «в Колумбии вместо дополнительных приработков имеют в виду случайные заработки. Это лишь подчеркивает более низкий статус занятости, которая их обеспечивает. В то же время их удельный вес сравнительно небольшой, и он уступает другим источникам семейных доходов, а также российским «дополнительным приработкам» [Encuesta... web].
В этой ситуации необходимо отметить низкий удельный вес таких источников доходов колумбийского сельского населения, как пособия и пенсии. Причина этого в том, что значительная часть сельских жителей Колумбии, особенно 20-30 лет назад, занятая в сельском хозяйстве неквалифицированным трудом, работала неофициально и не делала пенсионных отчислений. Результат этого - крайне низкий средний размер пенсий в современной сельской Колумбии, равно как и число самих ее получателей.

Мнение респондентов о сфере проявления деловой активности, возможностей развития малого предпринимательства в сельской местности, показывает, насколько повышается эффективность сельской экономики и занятости, и как изменяется стиль жизни сельского населения (см. табл. 3, 4).

Уровень таких категорий, как «туризм», «промышленность», «промыслы», свидетельствует об небольших возможностях в сфере малого предпринимательства в России, которые сводятся к торговле и сельскому хозяйству. К этому следует еще добавить работу в городе. Это является показателем временных, маятниковых, сезонных городских миграций для нахождения работы и заработка. Работа

Таблица 1

\section{Распределение ответов на вопрос об основных источниках средств существования} семьи респондента (по российской выборке), множественный выбор, \%

\begin{tabular}{|l|c|}
\hline \multicolumn{1}{|c|}{ Источник } & в целом по выборке, \% \\
\hline заработная плата за выполнение работы по найму & 69,2 \\
\hline доход от собственного сельскохозяйственного производства & 57,0 \\
\hline пособия, пенсии, стипендии & 60,3 \\
\hline доход от предпринимательской или коммерческой деятельности & 15,3 \\
\hline дополнительные приработки & 20,9 \\
\hline доход от работы в городе (периодической, временной) & 30,3 \\
\hline
\end{tabular}

Таблииа 2

Распределение ответов на вопрос об основных источниках средств существования семьи респондента (по колумбийской выборке), множественный выбор, \%

\begin{tabular}{|l|c|}
\hline \multicolumn{1}{|c|}{ Источник } & в целом по выборке, \% \\
\hline заработная плата за выполнение работы по найму & 32,9 \\
\hline доход от собственного сельскохозяйственного производства & 33,1 \\
\hline $\begin{array}{l}\text { доход от продажи ремесленной продукции, сувениров } \\
\text { собственного производства }\end{array}$ & 2,8 \\
\hline пенсии, пособия & 4,2 \\
\hline доход от предпринимательской или коммерческой деятельности & 27,3 \\
\hline случайные приработки & 13,4 \\
\hline доход от работы в городе (периодической, временной) & 11,2 \\
\hline
\end{tabular}


в городе перестает восприниматься как вынужденная, и является составной частью стиля жизни сельского населения.

Предпринимательская активность аграрного населения в Колумбии, как и России, проявляется, прежде всего, в сельском хозяйстве. Но если в России под предпринимательством в сельском хозяйстве чаще всего понимается мелкотоварное неформальное сельскохозяйственное производство, то в Колумбии сельскохозяйственное предпринимательство - это всегда товарное производство в рамках фермерского хозяйства. В этом случае имеется различие между теми, кто является самостоятельным фермером и работает в собственном хозяйстве и теми, кто работает по найму. К рабочим по найму относятся и более-менее успешные сельскохозяйственные рабочие, занятые на постоянной основе, так и безземельные временные и сезонные рабочие-батраки, фактически являющиеся сельской беднотой.

После сельского хозяйства основными сферами деловой и предпринимательской активности сельского населения колумбийские респонденты называли мелкую торговлю с нерегулярными заработками, которую обозначил каждый четвертый респондент. При этом процент распространения поездок на заработки в город среди колумбийцев - крайне низкие: согласно опросу, мелким предпринимательством сельское население Колумбии занимается гораздо чаще. В России же маятниковая трудовая миграция почти оттеснила сельское хозяйство с ведущей позиции в проявлении деловой активности.

Далее было проанализировано, как местоположение села (по признаку близости-отдаленности от города) влияет на восприятие жителями различных социальных практик и возможностей. Местоположение села как в Колумбии, так и в России, является значимым фактором трудоустройства жителей, определяя масштаб и форму трудовой миграции, тип сельскохозяйственной занятости, возможности самозанятости. Численность респондентов из пригородных и отдаленных сел в каждой стране составляла 190-220 человек (см. табл. 5).

Респонденты из пригородных сел в обеих странах чаще, чем респонденты из отдаленных сел, имеют собственное дело, ориентированное на потребителей-горожан - обычно в сфере производства и торговли сельхозпродукцией или в сфере услуг. Для них характерна более активная маятниковая трудовая

Таблица 3

Распределение ответов на вопрос об основных направлениях предпринимательской и деловой активности сельских жителей (по российской выборке), множественный выбор, \%

\begin{tabular}{|l|c|}
\hline \multicolumn{1}{|c|}{ Направление } & в целом по выборке, \% \\
\hline сельское хозяйство & 67,4 \\
\hline торговля (магазины, стационарные и неформальные торговые точки) & 30,3 \\
\hline работа в городе, отходничество & 61,7 \\
\hline охотничий и рыбный промысел, заготовка и сбыт дикоросов, туризм & 7,3 \\
\hline промышленность & 5,3 \\
\hline
\end{tabular}

Таблица 4

Распределение ответов на вопрос об основных направлениях предпринимательской и деловой активности сельских жителей (по колумбийской выборке), множественный выбор, \%

\begin{tabular}{|l|c|}
\hline \multicolumn{1}{|c|}{ Направление } & в целом по выборке, \% \\
\hline сельское хозяйство - фермерами на собственной или арендованной земле & 45,7 \\
\hline сельское хозяйство - наемными работниками у фермеров & 22,6 \\
\hline мелкая торговля или другие небольшие, нерегулярные заработки & 25,1 \\
\hline $\begin{array}{l}\text { небольшой несельскохозяйственньй бизнес (магазин, кустарное } \\
\text { производство, услуги и проч.) }\end{array}$ & 28,9 \\
\hline работа в городе, отходничество & 13,2 \\
\hline охотничий и рыбный промысел, заготовка и сбыт дикоросов, туризм & 1,8 \\
\hline
\end{tabular}


миграция, так как к общедоступному (в том числе респондентам из отдаленных сел) режиму длительного пребывания в городах на трудовой вахте добавляется доступный только для них режим высокопериодичных (часто ежедневных) поездок в город на работу. Для респондентов из отдаленных сел в обеих странах резко увеличивается значимость наличия работодателя (чаще всего производителя сельхозпродукции), так как организация собственного дела вне сельского хозяйства представляется им нереалистичной из-за отсутствия массового потребителя. Отличительная черта респондентов из отдаленных сел в России - их готовность в случае отсутствия работы и возможности уехать переключиться на полунатуральное производство сельхозпродукции; отличительная черта респондентов из отдаленных сел в Колумбии - надежда на случайные заработки и мелкий бизнес. В целом ответы российских и колумбийских респондентов из отдаленных сел отражают их социально-экономическую уязвимость и более высокую готовность к миграции. При этом, по мнению молодых респондентов независимо от местоположения села проживания, низкие доходы и отсутствие работы реже стано- вятся причинами отъезда, чем ограниченность возможностей и перспектив.

Весьма красноречиво, что жители отдаленных сел в России активнее используют ЛПХ в качестве источника доходов. Очевидно, этим они компенсируют свои меньшие возможности в других сферах по сравнению с жителями пригородных сел. Хотя, отметим, что жители пригородных сел тоже активно торгуют продукцией ЛПХ, что отражает универсальность данного вида малого сельскохозяйственного предпринимательства для РФ.

Распределение направлений предпринимательской и деловой активности, доминирующих в пригородных и отдаленных селах в России и в Колумбии, демонстрирует ведущие позиции сельскохозяйственного предпринимательства в отдаленных селах в России, очевидно, связанных с деятельностью населения в сфере ЛПХ (табл. 6).

Следующим в отдаленных селах с большим отрывом идет «работа в городе»- маятниковая трудовая миграция. В пригородных селах РФ именно это направление деятельности, по оценкам респондентов, заняло ведущую позицию; сельское хозяйство с заметным отрывом идет следом.

Таблица 5

Распределение ответов респондентов из пригородных и отдаленных сел в России и Колумбии на вопрос об основных источниках средств существования их семей, множественный выбор, \%

\begin{tabular}{|l|c|c|c|c|}
\hline \multirow{2}{*}{ Источник } & \multicolumn{2}{c|}{ РФ } & \multicolumn{2}{c|}{ Колумбия } \\
\cline { 2 - 5 } & $\begin{array}{c}\text { пригородные } \\
\text { села }\end{array}$ & $\begin{array}{c}\text { отдаленные } \\
\text { села }\end{array}$ & $\begin{array}{c}\text { пригородные } \\
\text { села }\end{array}$ & $\begin{array}{c}\text { отдаленные } \\
\text { села }\end{array}$ \\
\hline Заработная плата за выполнение работы по найму & 71,7 & 66,5 & 24,8 & 40,3 \\
\hline Предпринимательская деятельность & 19,9 & 10,0 & 27,4 & 25,0 \\
\hline Сельхозпроизводство, продажа продукции ЛПХ & 51,8 & 63,0 & 38,5 & 25,0 \\
\hline Случайные, нерегулярные, дополнительные заработки & 28,3 & 12,5 & 12,8 & 13,9 \\
\hline Работа в городе (периодическая, временная) & 34,5 & 25,5 & 12,8 & 5,6 \\
\hline
\end{tabular}

Распределение ответов респондентов из пригородных и отдаленных сел
на вопрос о направлениях предпринимательской и деловой активности
множественный выбор, \%
\begin{tabular}{|l|c|c|}
\hline Направление деловой активности & \multicolumn{2}{c|}{ РФ, \% } \\
\cline { 2 - 3 } & пригородные села & отдаленные села \\
\hline сельское хозяйство & 55,8 & 79,5 \\
\hline торговля & 29,2 & 28,5 \\
\hline работа в городе & 74,3 & 48,0 \\
\hline промышленность & 7,5 & 2,5 \\
\hline $\begin{array}{l}\text { охотничий и рыбный промысел, } \\
\text { заготовка и сбыт дикоросов, туризм }\end{array}$ & 6,2 & 12,0 \\
\hline
\end{tabular}




\section{СОЦИОЛОГИЯ И СОЦИАЛЬНЫЕ ТЕХНОЛОГИИ}

В Колумбии, напротив, сельскохозяйственное предпринимательство ассоциирующееся с фермерством, в большей степени развито именно в пригородных, а не в отделенных, селах. Подтверждает логику больший масштаб распространенности мелкой маргинальной торговли в отдаленных селах и маятниковой трудовой миграции (работой в городе) в пригородных (табл. 7).

Отметим также, что комментарии некоторых респондентов из обеих стран, сделанные ими при личном общении в ходе опроса, были весьма характерными и образными. Приведем здесь наиболее яркие высказывания двоих из них. Российский информант (мужчина 41 года из села Идолга около Саратова, электрик, занятый в режиме маятниковой миграции; в свободное время подрабатывает неофициально) критичен: «Люди считают, что если я работаю, подрабатываю, зарабатываю, значит, я плохой, я вор», «Если ты получил образование, то Идолга тебе не нужна, и ты Идолге не нужен»; считает необходимым опираться на собственные силь: «если будешь сидеть, как приклеенный, ничего не добьешься».

\section{Заключение}

Анализ официальной статистики и результатов анкетного опроса позволил выявить следующие общие черты в социальных практиках сельского населения России и Колумбии, относящихся к хозяйственно-экономической сфере, которые, по-видимому, являются универсальными для любой страны независимо от национальных традиций и уровня развития социума. Узость рынка труда и более низкое, чем в городе, качество жизни продуцируют распространение среди сельского населения вторичной и неформальной занятости, неквалифицированного труда, трудовой миграции в города - маятниковой или постоянной. Изменение характеристик внешней социально-экономической среды вызывает у сельского социума, независимо от национальных особенностей, похожую рациональную социальноповеденческую реакцию. В частности, сокращение возможностей трудоустройства ориентирует сельское население на малое предпринимательство и неформальную занятость, чаще всего в сельском хозяйстве и торговле, или на миграцию в города; близость к городу способствует множественности трудовых стратегий.

\section{СПИСОК ЛИТЕРАТУРЫ}

Андреенкова 2011 - Андреенкова А.В. Межстрановые сравнительные исследования в социальных науках: методология, этапы развития, современное состояние // Мир России. 2011. № 3. C. $125-154$.

Барсукова, Радаев web 2012 - Барсукова С.Ю., Радаев В.В. Неформальная экономика в России: краткий обзор // Экономическая социология. 2012. T. 13, № 2 // https://ecsoc.hse.ru/2012-132.html.

Таблица 7

Направления предпринимательской и деловой активности сельского населения в Колумбии, \%

\begin{tabular}{|l|c|c|}
\hline \multicolumn{1}{|c|}{ Направление деловой активности } & \multicolumn{2}{|c|}{ Колумбия, \% } \\
\cline { 2 - 3 } & пригородные села & отдаленные села \\
\hline $\begin{array}{l}\text { сельское хозяйство - фермерами на собственной или } \\
\text { арендованной земле }\end{array}$ & 62,4 & 33,3 \\
\hline сельское хозяйство - наемными работниками у фермеров & 35,9 & 15,3 \\
\hline $\begin{array}{l}\text { небольшие, нерегулярные заработки в сфере мелкой } \\
\text { торговли и т.п. }\end{array}$ & 14,5 & 38,9 \\
\hline $\begin{array}{l}\text { небольшой несельскохозяйственный бизнес (торговля, } \\
\text { кустарное производство, услуги и проч.) }\end{array}$ & 27,8 & 29,6 \\
\hline работа в городе & 15,4 & 5,6 \\
\hline $\begin{array}{l}\text { охотничий и рыбный промысел, заготовка и сбыт } \\
\text { дикоросов, туризм }\end{array}$ & 1,7 & 1,7 \\
\hline
\end{tabular}

Примечание. Источник: Encuesta... web. 
Бурдье web - Бурдье П. Различение: социальная критика суждения [Экономическая социология. 2005. Т. 6, № 3] // https://ecsoc.hse.ru/ data/2011/12/08/1208204931/ecsoc_t6_n3.pdf.

Вебер 1990 - Вебер М. Избранные произведения. М.: Прогресс, 1990.

Вебер 1994 - Вебер М. Основные понятия стратификации // Социологические исследования. 1994. № 5. C.169-183.

Веблен 1984 - Веблен Т. Теория праздного класса. М.: Прогресс, 1984.

Горбань web - Горбань Е.С. Обзор социологических теорий и интерпретация понятия «стиля жизни»: от классового общества до постмодерна [Экономическая социология. 2013. Т. 14, № 3] // https://ecsoc.hse.ru/2013-14-3.html.

Горшков, Крумм, Тихонова (ред.) 2009 - Российская повседневность в условиях кризиса / под ред. М.К. Горшкова, Р. Крумма, Н.Е. Тихоновой. М.: Альфа-М, 2009.

Дулина 2017 - Дулина Н.В. Социальноэкономическое развитие региона как гетерархической системы // Социальногуманитарный вестник Прикаспия. 2017. № 1-2 (6-7). С. 27-32.

Обследование... web - Обследование рабочей силы: стат. бюл. / Росстат. М., 2019 // https:// rosstat.gov.ru/compendium/document/13265.

Парамонова, Дулина 2015 - Парамонова В.А., Дулина Н.В. Статус города: теоретико-прикладное значение // Известия ВолгГТУ. Серия «Проблемы социальногуманитарного знания〉. 2015. № 9 (172). С. 30-34.

Пасовец 2017 - Пасовец Ю.М. К вопросу о региональном измерении современного российского общества // Вестник Воронежского государственного университета. Серия: История. Политология. Социология. 2017. № 1. С. $90-94$.

Российский... web - Российский статистический ежегодник. 2019 / Росстат. М., 2019 // https:// rosstat.gov.ru/folder/210/document/12994.

Рощина web-Рощзина Я.М. Дифференциация стилей жизни в поле досуга [Экономическая социология. 2007. Т. 8, № 4] // http:// www.hse.ru/mag/ecsoc/2007-8-4.html.

Федеральная... web - Федеральная служба государственной статистики // http://www.gks.ru/

Departamento... web - Departamento Administrativo Nacional de Estadнstica de Colombia (Национальный административный департамент статистики Колумбии, исп.) // http:// www.dane.gov.co/

Encuesta... web - Encuesta nacional de Calidad de Vida (ECV) // https://www.dane.gov.co/ index.php/estadisticas-por-tema/salud/ calidad-de-vida-ecv/

\section{REFERENCES}

Andreenkova A.V., 2011. Cross-National Comparative Studies in Social Sciences: Methodology, History of Development, State of the Art and Recent Trends, Mir Rossii, no. 3, pp. 125-154.

Barsukova S.Yu., Radaev V.V., 2012. Informal Economy in Russia: A Brief Overview, Ekonomicheskaya sociologiya, vol. 13, no. 2. URL: https://ecsoc.hse.ru/ 2012-13-2.html (accessed 28 June 2020).

Bourdieu P., 2005. Distinction: A Social Critique of the Judgement of Taste. Ekonomicheskaya sociologiya, vol. 6, no. 3. URL: https://ecsoc. hse.ru/data/2011/12/08/1208204931/ecsoc t6 n3.pdf (accessed 28 June 2020).

Weber M., 1990. Selected Works. Moscow, Progress.

Weber M., 1994. Basic concepts of stratification, Sociologicheskiye issledovaniya, no. 5, pp.169-183.

Veblen T., 1984. The Theory of the Leisure Class. Moscow, Progress Publ.

Gorban E.S., 2013. A Review of Sociological Theories and Interpretations of the Notion of «Lifestyle»: From Class Society to Postmodern, Ekonomicheskaya sociologiya, vol. 14, no. 3. URL: https://ecsoc.hse.ru/2013-14-3.html (accessed 26 June 2020).

Gorshkov M.K., Krumm R., Tikhonova N.E. (eds.), 2009. Russian daily life in a crisis. Moscow, Alpha-M Publ.

Dulina N.V., 2017. Socio-economic Development of the Region as a Heterarchic System, Social'nogumanitarnyj vestnik Prikaspiya, no. 1-2 (6-7), pp. 27-32.

Labor Force Survey: Statistical Bulletin, 2019. Rosstat. Moscow. URL: https://rosstat.gov.ru/ compendium/document/13265 (accessed 20 June 2020).

Paramonova V.A., Dulina N.V., 2015. City Status: Theoretical and Applied Value, Izvestiya VolgGTU, Seriya "Problemy social'no-gumanitarnogo znaniya”, no. 9(172), pp. 30-34.

Pasovets Yu.M., 2017. To a Question of Regional Measurement of Contemporary Russian Society, Vestnik Voronezhskogo gosudarstvennogo universiteta. Seriya: Istoriya. Politologiya. Sociologiya, no. 1, pp. 90-94.

Russian statistical yearbook, 2019. Rosstat. Moscow. URL: https://rosstat.gov.ru/folder/210/document/ 12994 (accessed 20 June 2020).

Roshchina Y.M., 2007. The Differences of Russian Life Styles in Leisure Time, Ekonomicheskaya sociologiya, vol. 8, no. 4. URL: http://www.hse.ru/ mag/ecsoc/2007-8-4.html (accessed 26 June 2020).

Federal State Statistic Service. URL: http:// www.gks.ru/ (accessed 20 June 2020). 


\section{СОЦИОЛОГИЯ И СОЦИАЛЬНЫЕ ТЕХНОЛОГИИ}

National Administrative Department of Statistics of Colombia. URL: http://www.dane.gov.co/ https:// www.dane.gov.co/index.php/estadisticas-por-tema/ salud/calidad-de-vida-ecv/ (accessed 20 June2020).
National Quality of Life Survey of Colombia. URL: https://www.dane.gov.co/index.php/ estadisticas-por-tema/salud/calidad-de-vidaecv/ (accessed 20 June 2020).

\section{Information About the Authors}

Mikhail M. Krasnov, Lecturer, Department of Planning and Management of Territorial Development, Faculty of Economics, Pedagogical and Technological University of Colombia, Avenida Central del Norte, 35-115, 150003 Tunja, Colombia, mikhail.krasnov@uptc.edu.co, https://orcid.org/0000-0002-3260-287X

Natalia A. Skobelina, Doctor of Sciences (Sociology), Associate Professor, Head of the Department of Sociology and Social Technologies, Volgograd State University, Prosp. Universitetsky, 100, 400062 Volgograd, Russian Federation, volnatmax@volsu.ru, https://orcid.org/0000-0002-2108-187X

\section{Информация об авторах}

Михаил Михайлович Краснов, преподаватель кафедры планирования и управления территориальным развитием, экономический факультет, Университет педагогики и технологий Колумбии, авенида Сентраль дель Норте, 35-115, 150003 г. Тунха, Колумбия, mikhail.krasnov@uptc.edu.co, https://orcid.org/0000-0002-3260-287X

Наталья Анатольевна Скобелина, доктор социологических наук, доцент, заведующая кафедрой социологии и социальных технологий, Волгоградский государственный университет, просп. Университетский, 100, 400062 г. Волгоград, Российская Федерация, volnatmax@volsu.ru, https://orcid.org/0000-0002-2108-187X 